\title{
Psychomotor Agitation
}

National Cancer Institute

\section{Source}

National Cancer Institute. Psychomotor Agitation. NCI Thesaurus. Code C117164.

Physical restlessness, often associated with increased motor activity. 